\title{
A Comparative Study of Intelligence in Children of Consanguineous and Non-consanguineous Marriages and its Relationship with Holland's Personality Types in High School Students of Tehran \\ ORIGINAL
}

Ali, Navidian, Pregnancy Health Research Center, Zahedan University of Medical Sciences, Zahedan, IR Iran. Email: alinavidian@gmail.com.

Ebrahim, Ebrahimitabas, Pregnancy Health Research Center, Zahedan University of Medical Sciences, Zahedan, IR Iran.

Nasser, Yousefi, University of Kurdistan. Email: naseryosefi@yahoo.com

\section{Azizollah, Arbabisarjou} (corresponding author), Pregnancy Health Research Center, Zahedan University of Medical Sciences, Zahedan, IR Iran. Email: arbabisarjou2007@gmail.com

\section{Abstract}

Introduction: The present research aims to study and compare intelligence in children of consanguineous and non-consanguineous marriages and its relation with Holland's personality types.

Methodology: This is a descriptive study and uses an ex-post facto design. The statistical population is comprised of all high school students of Tehran province in the school year 2010-2011. The sample size includes 1,221 students, 628 of whom are children of consanguineous marriages and 593 are children of non-consanguineous marriages. The researchers employed Raven's Progressive Matrices Test and Holland Code (RIASEC) Test for data collection.

Findings: T-test results indicate that there is no significant difference in intelligence between children of consanguineous marriages and those of non-consanguineous marriages. However, descriptive data indicate that the mean IQ in children of consanguineous marriages is one unit lower than those of non-consanguineous marriages. Also, the results of variance analysis reveal that the difference in intelligence between different personality types is significant. Tukey's post hoc test results indicate that students with an investigative personality type have a higher intelligence compared with those with other personality types. 


\section{Introduction}

Ever since the dawn of mankind, marriage has ensured the establishment of families and reproduction. Marriage has different forms and rules in different religions and ethnicities [Muller \& Young, 2001]. Consanguineous marriage is a prominent form of matrimony in the world, especially in our country. Consanguineous marriage is the marriage between two individuals with at least one common ancestor at four generations ago [Davati, Jafari, Kholdi, \& Sedaghat, 2009]. According to the World Health Organization (WHO), marrying one's second cousin or a closer individual is considered to be a consanguineous marriage [Teebi \& Farag, 1997]. The traditional assumption is that consanguineous marriages have multiple social and economic advantages such as the preservation of family wealth, increased social security, and better adaptation with the family of the spouse [Hussain, R, 2001, as quoted in Bildirici, Ersin \& Kokdener, 2011]. On the other hand, consanguineous marriage affects mortality, fertility, and health conditions. Most consanguinity-related diseases happen in the first few years of life [Hussain et al, 2001]. Numerous genetic disorders and diseases are reported to have originated from consanguineous marriage, including neural tube defect, congenital heart disease, autosomal recessive deafness, and visual defects such as early-onset retinal dystrophy, congenital glaucoma, enophthalmos, bilateral retinoblastoma, and congenital hypothyroidism )Shomali, Montazeri, Akrami, Heshmat \& Larijani, 2007]. Another issue affected by consanguineous marriage is intelligence. As intelligence is perceived in cellular components and nervous tissue and since it is a capacity affected by both nature and nurture, consanguineous marriage affects it by nature and heredity [Deary, Penke \& Johnson, 2010]. Wechsler defines intelligence as a set of capabilities for rational thought, logical and beneficiary behavior, and effective action to adapt to the environment [Biswanath et al, 2009]. Eysenck (1992) has defined three types of intelligence: type A which represents the biological aspect of intelligence, type $B$ which represents social intelligence, and type $C$ which is known as measured intelligence in intelligence tests. Eysenck believes that intelligence type $\mathrm{C}$ or measured intelligence has three elements: mental speed, persistence and the ability to recognize mistakes in solutions of a problem. The results of a study by Bashee (1977), as quoted by Woodley (2009), indicate that the extent to which consanguineous marriages affect IQ depends on the degree of kinship. Based on three cognitive ability tests, he found out that, on average, children of double-first cousins or bilateral relatives by blood up to the third degree of kinship score lower on intelligence compared with children of first cousins or third-degree marriages who, in turn, score lower on intelligence compared with children of non-consanguineous marriages. He also stated that children of bilateral third-degree marriages have more variance compared with third-degree marriages. According to Kamin (1980), socio-economic status is an important factor in determining the IQ of children of consanguineous marriagea. Also, Jensen (1983) concluded that consanguineous marriages reduce the IQ of children by 2.5 to 3.5 scores.

More recent studies indicate a significant decrease in the IQ of children of consanguineous marriages [Agrawal, Sinha \& Jensen, 1984; Badaruddo$z a, 2004]$. Also, Jensen declared that the majority of individuals with an IQ below 70 are children of consanguineous marriages. Buck (1957), as quoted by Woodley (2009), showed that mental retardation in children of third-degree consanguineous marriages is three times more frequent that in children of non-consanguineous marriages among Swedish families.

Morton's study (1978) indicated that mental retardation in children of consanguineous marriages is five times more frequent than in normal marriages. The study by Madhavan and Narayan (1991) demonstrated a considerable increase in mental retarda- 
tion in children of consanguineous marriages. They predicted a higher risk in second-degree marriages (marriages between uncles and aunts on the one hand and nieces and nephews on the other) which are customary in some areas of South India.

Another intelligence-related issue discussed in various studies is the relationship between intelligence and personality. Intelligence-related studies have a keen interest in the relationship between intelligence and personality [Sternberg \& Ruzgis, 1994]. Using Eysenck's definition of intelligence type $C$, the relationship between intelligence and personality can be studied. This model is based on the observation that different participants in the same IQ test respond differently to the same items. By identifying persistence and the ability to recognize mistakes as personality traits (which also include the need for progress as well), we can understand the relationship between intelligence and personality [Harris, 2003]. Cattell (1971) speaks of fluid and crystalized intelligence. He defines fluid intelligence as the perception of complicated relations when there is no source to explain such complicacies and crystalized intelligence as accumulated knowledge. According to Cattell, these two types of intelligence are related to one another to some extent. Individuals with higher levels of fluid intelligence are able to invest more in cognitive matters and thus acquire more knowledge. Furthermore, social opportunities such as education and also personal differences in motivation and personality are other factors determining crystalized intelligence. In a meta-analysis, Ackerman and Heggestad investigated the studies related to intelligence and personality and concluded that openness to experience is correlated with both types of Cattell's intelligence.

Studies also indicated that intelligence has a positive and average relationship with openness to experience, need for progress, and creativity [Harris, 2003]. Crano, Kenny and Campbell reported that intelligence, as the ability to work with abstract concepts, predicts students' progress and skill acquisi- tion in their future career [Crano, Kenny \& Campbell et al, 1972]. Some researchers believe that the relationship between intelligence and progress is affected by personal motivation for progress and skill acquisition [Nisser et al., 1996].

According to Holland, the hierarchy or success level in a job during the process of occupational decision-making is determined first of all by an individual's self-evaluation. In this theory, intelligence is given less importance than personality and will. Additionally, the element of intelligence is implicitly considered in categorizing personality types. For instance, individuals with the investigative personality type are generally more intelligent and naturally have skills such as analytical and abstract reasoning [Zonker, translated by Nazari, 2009].

Since few studies have been conducted on the relationship between intelligence in consanguineous and non-consanguineous marriages and on the relationship between intelligence and personality types, the present study analyzes and compares intelligence in children of consanguineous and non-consanguineous marriages and its relationship with personality types in Iran.

\section{Research Hypotheses}

There is a significant difference in intelligence between children of consanguineous marriages and those of non-consanguineous marriages.

There is a relationship between intelligence on the one hand and personality types, social class, order of birth, and number of children on the other hand.

\section{Methodology}

This is a descriptive study and uses an ex-post facto design. The statistical population is comprised of all students living in Baharestan city, Tehran, Iran. 
The sample population was selected using cluster sampling. Required data on members of the sample population were extracted from 1,221 student files from 6 different schools. 628 members of the sample population are children of consanguineous marriages and 593 are children of non-consanguineous marriages. The collected data concern the type of parents' marriage, IQ, order of birth, number of children, economic status, and the first tendency of sampled students based on Holland's personality types. The data on intelligence were collected using Raven's Progressive Matrices Test for adults; the data on personality types were collected using Holland's Interest Scale Test; and, the data on economic status, order of birth, and number of children were collected using self-report questionnaires administered among members of the sample.

\section{Measurement Instruments}

\section{Raven's Progressive Matrices Test}

Raven's Progressive Matrices Test is a non-verbal general intelligence test developed in 1983 by British psychologist Raven. Simpler colored forms of this test are developed for children of 5-11 years and mentally retarded adults and its advanced form is developed for adults. The test includes 60 visual items - in 5 sets (, , B, C, D, and E) of 12 questions - and is designed to evaluate Spearman's general intelligence factor. Burke (1972), as quoted by Moghimi Azar (1998), reported an internal consistency coefficient of between 0.89 and 0.97 for Raven's test with a sample population of 500 American adults of different ages. He also found out that split-half coefficients of correlation are higher in Raven's test than in Wechsler's test and concluded that these data confirm the reliability of the test. Steins (1956), as quoted by Moghimi Azar (1998) examined the test-retest reliability of Raven's test with one-week, one-month, and threemonth intervals and obtained values of $0.89,0.81$, and 0.87 , respectively. In a study on 3,010 Iranian subjects for the standardization of the test, Barahini (1977) obtained satisfactory coefficients of reliability and validity. Additionally, in another study on the age group of 12 to 18 and higher, Pachari (2005) reported an internal consistency coefficient of between 0.80 and 0.84 and a reliability coefficient of between 0.88 and 0.91 for this test (quoted by Afruz and Motamedi, 2005). Other researchers reported a validity of 0.86 and a test-retest reliability of between 0.80 and 0.90 [Ahmadi, 1993].

\section{Holland Code (RIASEC) Test}

RIASEC is a widely used interest scale test. It has versions in more than 20 languages, can be administered by computers, and also supports computer reports. Hosseinian and Yazdi (1998) examined the reliability and validity of RIASEC. Its reliability was assessed by the correlation between each item and the test's total score, internal consistency, and splithalf methods; and its validity was assessed by the correlation between the scales. The results indicated that the scales of the test have a high reliability and validity at a significance level of 1 percent.

\section{Findings}

Table 1 demonstrates that there is no significant difference in intelligence between children of consanguineous and non-consanguineous marriages.

Table 2 demonstrates that the mean IQ has a decreasing trend from the first to the last child.

According to table 3, students with the investigative personality type show a better performance in intelligence tests.

Table 4 shows that there is a significant difference in intelligence only between mean square values of personality types and that the difference is not significant in other aspects. Also, the results of table 5 indicate that this difference in intelligence is to the advantage of individuals with the investigative personality type.

As demonstrated in the table $\mathbf{5}$, there is a sig- 
Table 1. Descriptive data and t-test results regarding intelligence in children of consanguineous and non-consanguineous marriages

\begin{tabular}{|l|c|c|c|c|c|c|c|}
\hline & Marriage & N & Mean & Std. deviation & df & T & P \\
\hline Intelligence & Consanguineous & 623 & 49.107 & 96.12 & & & 1219 \\
\cline { 2 - 7 } & Non-consanguineous & 593 & 67.108 & 12 & $644.1-$ & 1.0 \\
\hline
\end{tabular}

Table 2. Descriptive statistics regarding intelligence and order of birth

\begin{tabular}{|c|c|c|c|c|}
\hline \multicolumn{2}{|c|}{ Order of birth } & Mean & Std. deviation & N \\
\hline Intelligence & First child & 58.108 & 98.12 & 402 \\
\hline Middle children & 12.108 & 52.12 & 403 \\
\hline Last child & 66.107 & 94.12 & 403 \\
\hline total & 12.108 & 48.12 & 1208 \\
\hline
\end{tabular}

Table 3. Descriptive statistics regarding intelligence in various personality types

\begin{tabular}{|c|c|c|c|c|}
\hline \multicolumn{2}{|c|}{ Personality type } & Mean & Std. deviation & N \\
\hline Intelligence & Investigative & 805.114 & 231.11 & 216 \\
& Realistic & 178.106 & 356.12 & 342 \\
& Conventional & 459.107 & 981.11 & 74 \\
& Enterprising & 226.106 & 503.13 & 243 \\
& Social & 521.107 & 021.11 & 167 \\
& Artistic & 757.106 & 662.11 & 173 \\
\hline Total & & 066.108 & 496.12 & 1215 \\
\hline
\end{tabular}

Table 4. Variance analysis results

\begin{tabular}{|c|c|c|c|c|c|c|}
\hline \multirow{2}{*}{ Variables } & Sum of squares & Mean square & df & F & P \\
\hline \multirow{2}{*}{ Intelligence } & Personality type & 237.12225 & 668.16 & 5 & 668.16 & 001.0 \\
\hline & Social class & 325.1221 & 331.305 & 4 & 915.1 & 106.0 \\
\hline & Order of birth & 512.6 & 256.3 & 2 & 020.0 & 980.0 \\
\hline
\end{tabular}


Table 5. Pairwise comparison of means on the intelligence scale

\begin{tabular}{|c|c|c|c|}
\hline Pairs & Mean difference & Std. error & $\mathbf{p}$ \\
\hline Investigative & 62.7 & 05.1 & 01.0 \\
Realistic & 34.7 & 63.1 & 01.0 \\
\hline $\begin{array}{c}\text { Conventional } \\
\text { Enterprising }\end{array}$ & 57.8 & 13.1 & 01.0 \\
Social & 28.7 & 24.1 & 01.0 \\
Artistic & 04.8 & 23.1 & 01.0 \\
\hline
\end{tabular}

nificant difference between the mean intelligence of the investigative type $(=114.805)$ and that of the other personality types. However, differences are not significant between other pairs of personality types.

\section{Discussion and Conclusion}

The results of pairwise comparison of mean intelligence scores in children of consanguineous and non-consanguineous marriages revealed that there is no significant difference between these two groups in terms of intelligence. These results are not consistent with the results of studies by Agrawal, Sinha and Jensen (1984) and Badaruddoza (2004). It seems that the findings of the study by Jensen (1983) can better explain these results. Jensen declared that the majority of individuals with an IQ below 70 are children of consanguineous marriages. Since this study was conducted among high school students, they fall into the category of normal people as they have managed to continue their studies up to high school. Less intelligent individuals have probably failed to reach this stage of education and have been transferred to schools for special education. Yet again, despite the insignificance of mean differences in intelligence, a look at the descriptive data reveals that the mean IQ in children of consanguineous marriages is one unit lower than those of non-consanguineous marriages. This result is in alignment with the findings of Jensen (1983). Jensen concluded that consanguineous marriages reduce IQ by 2.5 to 3.5 scores. The results of the present study are not consistent with those of Madhavan and Narayan (1992). However, IQ assessment among different personality types revealed that there is a difference between Holland's personality types in terms of intelligence and that individuals with the investigative personality type score the highest on intelligence. In fact, individuals with the investigative personality type are considerably more intelligent compared with other personality types. This conclusion is in alignment with the results of a study by Hosseinian and Yazdi (2004) on the occupational interests of brilliantly talented 
university students. They found that the majority of talented students, despite having interests different from their own fields of study, have an investigative tendency. Also, in his research titled "An Analysis of the Relationship between the Personality Traits of Freshman and Senior Students of Civil Engineering in Sharif University and Iran University of Science and Technology," Barati (1995) found that the prominent personality type among those students is the investigative type. According to the study by Ackerman and Heggestad (1997), there is a significant relationship between openness to experience, from the big five personality traits, and intelligence. The study by Harris (2003) also confirms the idea that intelligence is correlated with openness to experience, creativity, and the need for progress.

\section{References:}

1. Ackerman, P. L., \& Heggestad, E. D. (1997). Intelligence, personality, and interests: Evidence for overlapping traits. Psychological Bulletin, 121(2), 219-245.

2. Agrawal, N., Sinha, S. N., \& Jensen, A. R. (1984). Effects of inbreeding on Raven matrices. Behavior Genetics, 14, 579-585.

3. Ahmadi A, (1993). The project of normalization of Raven's test in the country, Tehran: office for consultation and research, ministry of education

4. Badaruddoza (2004).Effect of inbreeding on Wechsler intelligence test scores among North Indian children. Asian Pacific Journal of Public Health,16, 99-103.

5. Bildirici, M., Ersin, O., \& Kokdener, M. (2011). Genetic structure, consanguineous marriages and economic development: Panel co-integration and panel co-integration neural network analyses. Expert Systems with Applications, 38, 53-63.

6. Biswanath, S., Geoffrey , L. B., Marijn, K., Robert, A. Z., Gail, P. J., Gil, W., Robert, R. C., Daniel , J. L., William, G., Chandrasekhar, N. (2009). Prediction of periventricular leukomalacia. Part II: Selection of hemodynamic features using computational intelligence. Artificial Intelligence in Medicine, 46, 217-231.
7. Cattell, R. B. (1971). Abilities: Their structure, growth, and action. Boston: Houghton Mifflin.

8. Crano, W. D., Kenny, D. A., \& Campbell, D. T. (1972). Does intelligence cause achievement?: a cross-lagged panel analysis. Journal of Educational Psychology, 63, 258-275.

9. Deary, I. J., Penke, L., \& Johnson, W. (2010).The neuroscience of human intelligence differences. Nature Reviews. Neuroscience, 11(3), 201-211.

10. Davati A, Jafari F, Kholdi N, Sedaghat M, 2009, studying the frequency of consanguineous marriages in Tehran and the related factors, the scientific magazine of Semnan university of medical science, 4(10), 287-95

11. Eysenck, H. J. (1992). Intelligence: the one and the many?. In D. K. Detterman (Ed.), Current topics in human intelligence, Vol. 2: is mind modular or unitary? (pp. 83-116). Norwood, NJ: Ablex.

12. Jensen, A. R. (1983). Effects of inbreeding on mental ability factors. Personality and Individual Differences, 4, 71-87.

13. Harris, J.(2003). Measured intelligence, achievement, openness to experience, and creativity. Personality and Individual Differences, 36, 913-929.

14. Hosseinian S, Yazdi M, 1998, investigating the preliminary credibility of occupational and educational interest test, news and researches of consultation periodical, 1, 77

15. Hosseinian S, Yazdi M, 1999, occupational guidance by correspondence of personality with job environment and normalization of SDS test, bill of Al-Zahra University research faculty, Al-Zahra University science and research periodical

16. Hussain, R., Bittles, A. H., \& Sullivan, S. G. (2001). Early childhood mortality in Muslim populations of India and Pakistan. American Journal of HumanBiology,13, 177-187.

17. Kamin, L. J. (1980). Inbreeding depression and IQ. Psychological Bulletin, 87, 469-478.

18. Madhavan, T., \& Narayan, J. (1991).Consanguinity and mental retardation. Journal of Mental Deficiency Research, 35, 133-139.

19. Morton, N. E. (1978). Effect of inbreeding on IQ and mental retardation. Proceedings of the National Academy of Sciences, 75, 3906-3908.

20. Muller, R. F., Young, I. D. (2001). Emery's Elements of Medical Genetics, Edinburgh; Churchill Livingston.

21. Neisser, U., Boodoo, G., Bouchard, T. J. Jr., Boykin, A. W., Brody, N., Ceci, S. J., Halpern, D. F., Loehlin, J. C.,Perloff, R., Sternberg, R. J., \&Urbina, S. (1996).Intelligence: knowns and unknowns. American Psychologist, 51, 77-101. 


\section{INTERNATIONAL ARCHIVES OF MEDICINE

22. Rashid Shomali S, Montazeri V, Akrami M, Heshmat R, Larijani B, 2007, study of the frequency and distribution of consanguineous marriages in three consecutive generations of individuals with diabetes and osteoporosis, Iranian magazine of diabetes and lipid, 1(7), 85-97

23. Sternberg, R. J., \&Ruzgis, P. (1994).Personality and intelligence. Cambridge, UK: Cambridge University Press.

24. Teebi, A. S., Farag, T. I. (1997) .Genetics disorders among Arab population. New York: O xford university press.

25. Woodley, A. M. (2009). Inbreeding depression and IQ in a study of 72 countries. Intelligence, 37, 268-276.

26. Zonker V.G, 2006, the holistic approach to occupational consultation, translated by Nazari et al. Tehran: SAMT publication

\section{Comment on this article:}

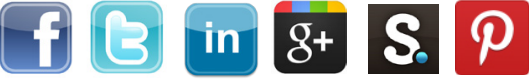

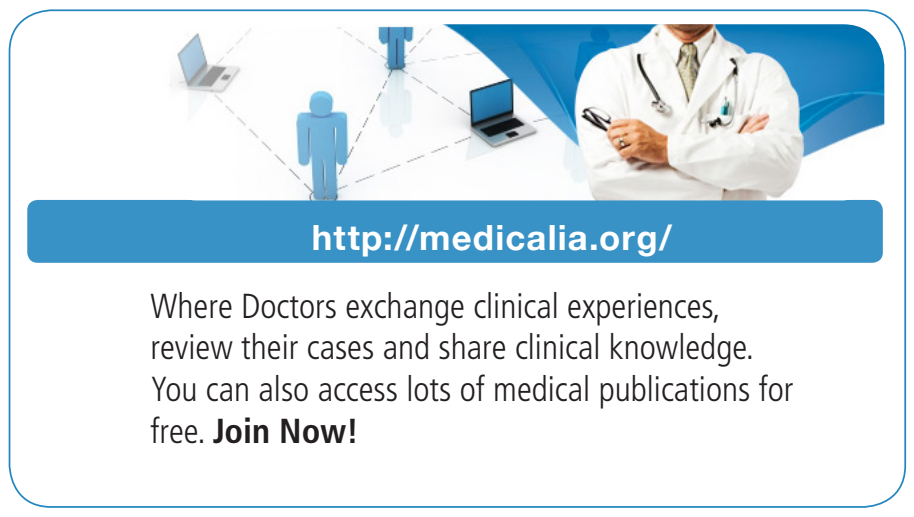

\section{Publish with iMedPub}

\section{http://www.imed.pub}

International Archives of Medicine is an open access journal publishing articles encompassing all aspects of medical science and clinical practice. IAM is considered a megajournal with independent sections on all areas of medicine. IAM is a really international journal with authors and board members from all around the world. The journal is widely indexed and classified Q1 in category Medicine. 